\title{
Media activity and public spending
}

\author{
Christian Bruns • Oliver Himmler
}

Received: 25 January 2009 / Accepted: 5 May 2010 / Published online: 19 June 2010

(C) The Author(s) 2010. This article is published with open access at Springerlink.com

\begin{abstract}
Politicians seeking reelection need voters to know what they have done for them. Thus, incentives may arise to spend more money where media coverage is higher. We present a simple model to explain the allocation of public spending across jurisdictions contingent on media activity. A politician seeking to maximize the probability of reelection will shift more money to jurisdictions where an extra dollar raises more votes because a larger share of the electorate is informed about his policy. The main prediction of the model is that media activity is higher in the core areas of media markets. This implies higher spending levels there and lower spending levels in remote jurisdictions. Empirical support for this prediction is found using United States data on county-level federal grant allocation, Designated Market Areas and the location of licensed television stations.
\end{abstract}

Keywords Federal funds · Information · Television · Elections

JEL Classification $\quad$ D7 $\cdot$ D8 $\cdot$ H7

\section{Introduction}

Do politicians channel more funds to places where media activity is higher? Political actors need voters to know what they have done for them. Since voters nowadays heavily rely on commercial mass media such as television, newspapers or radio to obtain

\footnotetext{
C. Bruns $(\varangle) \cdot$ O. Himmler

Göttingen University, Platz der Göttinger Sieben 3,

37073 Göttingen, Germany

e-mail: cbruns@uni-goettingen.de

O. Himmler

e-mail: ohimmle@uni-goettingen.de
} 
political information (Horrigan et al. 2004), politicians strive for media attention. However, the mass media typically bias coverage towards certain groups (Hamilton 2004; Strömberg 2004a). Thus, political benefits to those groups are more likely to attain media attention and make the affected voters consider the benefits when casting the ballot. Consequently, the payoff from funds in terms of votes is higher in these informed groups. This is why politicians face incentives to provide favorable policies to voters targeted by mass media.

In this paper, we examine whether local television news, which are the most popular source of political information in the United States (Napoli and Yan 2007), affect the allocation of federal grants. More precisely, we are interested in whether a geographic pattern of grant allocation exists which reflects a well-documented bias in local TV news programming: local news content focuses on the core areas of TV markets where the majority of TV stations is located (Adams 1980; Alesina and Trautman 2008; Heider 2000; Kaniss 1997). Thus, political actions in the core area are more likely to receive coverage which suggests that voters in that area are better informed about local politics than voters in remote regions. Due to this publicity effect, the amount of funds a location is awarded should systematically decline in distance to the core area of a TV market.

We analyze the relation between TV markets and public spending both theoretically and empirically. First, we present a simple model based on Strömberg (2004a,b) which serves to establish the link between local TV news and grant allocation. We show that television stations bias their news programs towards the markets' core areas because news production is less expensive there. As a consequence, in these regions there are more voters who are informed about their local politics. Then, the model explains how this information structure in the electorate affects a politician's incentives for strategic grant allocation. The main prediction of the model is that politicians direct more funds to areas close to media centers.

We test this prediction empirically using US county-level data. The dependent variable is the amount of federal grants per capita allocated to a county. Using a county's distance to the nearest media city in the market as our main explanatory variable, we find a substantial effect of distance on grant spending. A county which is located twice as far away as the mean distance receives $3.4 \%$ less in grants per capita which makes for an average total loss of about $\$ 2.8$ million per county per annum.

Our analysis builds on the pioneering work by Strömberg $(2004 \mathrm{a}, \mathrm{b})$ on the influence of mass media on fiscal policy. In a formal model, Strömberg (2004a) shows that certain groups of voters receive favorable policies when the mass media report more heavily on campaign promises concerning these groups. Analyzing data from the United States, Strömberg (2004b) tests empirically whether better informed groups in the electorate receive favorable policies. He finds that counties where many households owned a radio received more funds from a major New Deal program in the 1930s. In contrast to Strömberg's empirical paper, our paper examines how policy is affected by the geographic distribution of information which results from biased news programming in a market where everyone has access to the medium. Other research that deals with the media's role for accountability includes Snyder and Strömberg (2010), who find empirical evidence that newspaper coverage affects voters' information about their US House representatives. A better fit of newspaper markets with districts is found to 
increase information levels, resulting in more accountable Congressmen. Besley and Burgess (2002) also deal with the media's role for political accountability. They find that state governments in India provide more public food and calamity relief in hard times when newspaper circulation in the respective state is higher.

We proceed as follows. While the next section presents the theoretical model, Sect. 3 gives a description of the data and estimation approach. Empirical results are presented in Sect. 4. Section 5 concludes.

\section{Model}

The model builds on the framework by Strömberg (2004a,b). A politician distributes a given budget within his constituency. From now on, we refer to the politician as a US governor who receives grants from the federal government and allocates the money across counties in his state. The governor distributes grants strategically in order to win the next election. He knows that funds generate more votes in counties where many voters attribute the benefits derived from grant spending to him. He further knows that the share of these informed voters is larger in counties which are extensively covered by local television news. The model shows that economic forces make local television stations broadcast more news from counties located in the core area of a TV market. This geographical bias in local news programming yields lower shares of informed voters in remote counties and larger shares of informed voters in core areas. Thus, incentives arise for the governor to spend more in these core areas. ${ }^{1}$

The timing of the game which is described in the next section goes as follows: the governor distributes grants across counties. Then, the TV stations decide on their reporting strategy and voters choose a station to watch. Finally, an election takes place.

The governor's allocation problem. The governor aims at winning votes by allocating total grants $G$ across the counties $c=1,2, \ldots, C$ in his state such that

$$
\sum_{c} p_{c} \cdot g_{c}=G
$$

where $g_{c}$ denotes grant spending per capita and $p_{c}$ the population in county $c$. A voter $v$ in county $c$ enjoys utility $\omega_{c}=\ell_{c} \cdot \omega\left(g_{c}\right)$ from grant spending. We assume $\omega^{\prime}>0$, $\omega^{\prime \prime}<0$ and $\omega^{\prime}(0)=\infty$. The parameter $\ell_{c}$ implies that voters may value grant monies differently across counties.

Voter $v$ votes for the incumbent if his total utility under the incumbent's regime exceeds some reservation utility $\overline{\omega_{v}}$ :

\footnotetext{
1 At first glance, the choice of telling the story from a governor's perspective may appear arbitrary, since there is a large number of other players involved in the allocation procedure (such as senators, House members, mayors, or non-governmental organizations). However, a large share of federal funds is distributed to local recipients via the state administration. As states often enjoy quite some discretion in the allocation decisions (Lee 2003), we believe governors as chief executives of their states to be very important players in the allocation process. However, it is important to notice that local television affects the incentives of all players involved in the allocation process in the same way: a higher probability to receive coverage implies more political benefits for voters.
} 


$$
\tau_{v} \cdot \omega_{c}\left(g_{c}\right)-\sigma_{v}-\delta \geq \overline{\omega_{v}},
$$

and for a challenger otherwise. Besides grant spending, voters evaluate the incumbent in terms of ideology. Voter $v$ 's ideological position is described by $\sigma_{v}+\delta$, where $\sigma_{v}$ denotes a personal component and $\delta$ is the incumbent's general popularity in the electorate; both are random variables and may take on positive as well as negative values (see Persson and Tabellini 2000).

The indicator variable $\tau_{v}$ introduces the media effect into the model. $\tau_{v}$ equals one if voter $v$ attributes grant spending to the governor and zero otherwise. Thus, only informed voters consider grant spending in their voting decision. We assume that television news constitutes the only source of information about grant monies. ${ }^{2}$ In the next section, we show that television stations bias their news programs towards counties which are located in the TV market's core area. Consequently, the share of informed voters, $\phi_{c}$, for whom $\tau_{v}=1$ is larger in those counties and smaller in remote counties.

Local TV news. We assume that the television market is congruent with the state territory such that the electorate and the TV audience coincide. Two TV stations $A$ and $B$ compete for audience by broadcasting local news. Each station allocates total air time $N$ across counties such that $\sum_{c} n_{c}^{s}=N$, where $n_{c}^{s}$ is the news time devoted to county $c$ by station $s=A, B$. As the probability of a single vote being decisive is zero, voters consume news for its entertainment value only. They like to know what is going on in their community and their expected utility of watching a station's news is $u_{c}\left(n_{c}^{s}\right)=\phi\left(n_{c}^{s}\right) \cdot \bar{u}_{c} . \phi$ denotes the probability that a voter actually catches sight of a newscast. We assume $\phi^{\prime}\left(n_{c}\right)>0, \phi^{\prime \prime}\left(n_{c}\right)<0$ and $\phi^{\prime}(0)=\infty$. $\bar{u}_{c}$ denotes the exogenous utility a voter in county $c$ derives from seeing the news from his resident county. In other words, a voter knows that his expected utility from seeing an interesting newscast increases in the news time a station devotes to his home county. A voter $v$ chooses to watch station $A$ if

$$
u_{c}\left(n_{c}^{A}\right)-u_{c}\left(n_{c}^{B}\right) \geq \xi_{v}
$$

and station $B$ otherwise. The parameter $\xi_{v}$ denotes how voter $v$ evaluates fixed characteristics of station $A$ relative to station $B$ in terms of fixed characteristics, such as sympathy for anchormen, the style of presenting news or the ideological bias of a station. A positive value of $\xi_{v}$ implies that voter $v$ favors station $B$ whereas negative values indicate that station $A$ is favored. $F$ denotes the distribution function of $\xi_{v}$ with density $f$. Consequently, a voter watches station $A$ 's newscasts with probability $F\left[u_{c}\left(n_{c}^{A}\right)-u_{c}\left(n_{c}^{B}\right)\right]$.

Having described the demand for news, we now turn to the supply side. When television stations decide on which events in their market to cover, they have to consider the costs of news production. Kaniss (1997) and Heider (2000) argue that it is more expensive to report from distant counties for a number of reasons. First, the set-up costs of sending a news team to remote areas are higher. Long travel time often means overtime payments and higher expenditures for gasoline, meals and hotels.

\footnotetext{
2 We make this assumption for ease of exposition. Obviously, there are alternative sources like newspapers, radio or social contacts.
} 
Further, it may be necessary to purchase satellite time to immediately transfer a report to the newsroom. The alternative of employing freelancers is also expensive because freelance fees are often relatively high (Heider 2000). Second, as journalists usually reside in the core area of a media market, they find gathering information to be easier there than in remote counties. This is because they have better access to contact persons and a more comprehensive knowledge of local institutions in the core area (Kaniss 1997). Since budgets for the production of news are rather low (Kaniss 1997), geographical cost differentials should critically affect the decision of assignment editors. Being situated at the same place, both stations $A$ and $B$ face the same marginal cost of reporting from a county, $k_{c}$. These costs are high in distant counties whereas they are low in counties near the stations.

Both stations maximize expected profits with revenues coming from advertising. Advertisers on local television usually are less concerned with targeting specific sociodemographic groups than advertisers in newspapers (Kaniss 1997). Consequently, both stations simply maximize their audience regardless of composition and we normalize advertising revenues per viewer to one. Station $A$ maximizes expected profit

$$
E\left[\pi^{A}\right]=\sum_{c}\left[p_{c} \cdot F\left[u_{c}\left(n_{c}^{A}\right)-u_{c}\left(n_{c}^{B}\right)\right]-k_{c} \cdot n_{c}^{A}\right]
$$

subject to the air time constraint, and stations B's optimization problem is identical. Both stations decide simultaneously and non-cooperatively on the allocation of news time across counties. As the two stations face exactly the same optimization problem, in the unique Nash-Equilibrium ${ }^{3}$ the stations do not differ in the amount of news they broadcast from each county. Thus, equilibrium news allocation is given by a pair of strategies $\left(\mathbf{n}^{\mathbf{A}}, \mathbf{n}^{\mathbf{B}}\right)$ satisfying $n_{c}^{A}=n_{c}^{B}=n_{c}^{*}$, the air time constraint and the first-order condition

$$
p_{c} f \phi_{c}^{\prime}\left(n_{c}^{*}\right) \bar{u}_{c}-k_{c}=\lambda, \quad \lambda>0 .
$$

Eq. 5 implies that in equilibrium the marginal effect of a news unit on expected profit must be equal across all counties. In particular, Eq. (5) summarizes the message of the model regarding news time allocation. Assuming that the density $f(0)=1$ for $n_{c}^{A}=n_{c}^{B}=n_{c}^{*}$, we obtain the equilibrium news $n_{c}^{*}=n^{*}\left(k_{c}, p_{c}, \bar{u}_{c}\right)$. The stations broadcast more news about counties where producing news is less expensive (low $k_{c}$ ), where the intrinsic utility of watching the news is higher (high $\bar{u}_{c}$ ) and where the population is large (high $p_{c}$ ).

The amount of news from a county determines the share of informed voters, $\phi_{c}=\phi\left(n_{c}^{*}\left(k_{c}, p_{c}, \bar{u}_{c}\right)\right.$. Our main focus is on the result that more voters obtain infor-

\footnotetext{
${ }^{3}$ Basically, the model of competition between the two television stations is analogous to models of redistributive politics as introduced by Lindbeck and Weibull (1987) and extended by Dixit and Londregan (1996). As the basic model has already attained textbook status (see, e.g., Persson and Tabellini 2000) we abstain from extensively proving uniqueness and existence of the Nash-Equilibrium in this simple setting. Lindbeck and Weibull (1987) or Strömberg (2004a) clearly characterize equilibrium strategies and give proof. We assume $F$ to be of a form which satisfies the concavity condition for the objective functions of both stations for existence of equilibrium.
} 
mation in counties where the reporting costs, $k_{c}$, are low. Combined with our argument on the geography of reporting costs, the model predicts that TV newscasts contain less news from remote counties. Consequently, the share of informed voters in a county decreases in distance to the center of the TV market.

Strategic Allocation of Grants. Having determined the shares of informed voters in the counties, we can now compute the expected number of votes for the governor. For simplicity, we assume that $\sigma_{v}+\overline{\omega_{v}}$ in (2) is distributed uniformly with mean $m_{c}$ and density $\psi_{c}$. Let $\gamma_{c}$ denote voter turnout in county $c$. Then, the expected number of votes for the governor is given by the left hand side of

$$
\sum_{c} \gamma_{c} p_{c}\left(\frac{1}{2}+\psi_{c}\left(\phi_{c} \cdot \omega_{c}-m_{c}-\delta\right)\right) \geq \frac{1}{2} \sum_{c} \gamma_{c} p_{c} .
$$

Inequality (6) states that the governor wins the election if he accumulates more than half of all votes cast. Apparently, for any allocation of grants it depends on the realization of the general popularity shock, $\delta$, whether (6) is satisfied and the incumbent wins the election. Contingent on grant allocation the probability of reelection, $P$, is given by

$$
P=\Omega\left[\frac{1}{\sum_{c} \gamma_{c} p_{c} \psi_{c}} \sum_{c} \gamma_{c} p_{c} \psi_{c}\left(\phi_{c} \cdot \omega_{c}-m_{c}\right)\right],
$$

where $\Omega$ denotes the distribution function of $\delta$. In equilibrium, the optimal allocation of grants $\mathbf{g}^{*}$ which maximizes the probability of reelection satisfies the first-order condition

$$
\gamma_{c} \cdot \psi_{c} \cdot \phi_{c} \cdot \ell_{c} \cdot \omega^{\prime}\left(g_{c}^{*}\right)=\mu, \quad \mu>0
$$

and the budget constraint. ${ }^{4}$ Equation (7) implicitly defines the equilibrium spending levels $g_{c}^{*}=g^{*}\left(\gamma_{c}, \psi_{c}, \phi_{c}, \ell_{c}\right)$. Since $\omega\left(g_{c}\right)$ is concave, it is easy to see that counties with greater electoral clout $\left(\gamma_{c} \cdot \psi_{c} \cdot \phi_{c} \cdot \ell_{c}\right)$ receive more grants. Specifically, the governor directs more grants to counties where voter turnout $\left(\gamma_{c}\right)$ is high, where many swing voters live (high $\psi_{c}$ ), where an extra dollar generates more utility (high $\ell_{c}$ ) and where the share of informed voters is large (high $\phi_{c}$ ). This is intuitively reasonable, because larger values of each of these factors imply that an extra dollar is converted more effectively into votes. Thus, more funds are channeled to counties with greater electoral clout while counties with lower levels of electoral clout receive less money. This allocation of funds equalizes the marginal payoff of funds across counties.

The central message of the model for the empirical analysis is that the governor allocates more money to counties which are located near or in the core area of a TV market.

\footnotetext{
4 Since $\omega(g)$ is concave, the Hessian of the incumbent's payoff function is a diagonal matrix where all elements on the diagonal are negative. Thus, the Hessian is negative definite and the incumbent's payoff function is concave. Finally, as the constraint set is convex, $\mathbf{g}^{*}$ constitutes a unique global constrained maximum.
} 
This follows directly from the result that counties with larger shares of informed voters $\left(\phi_{c}\right)$ receive more grants. We know that $\phi_{c}=\phi\left(n_{c}^{*}\left(k_{c}, \bar{u}_{c}, p_{c}\right)\right)$ and also that the TV stations broadcast more news from less distant counties due to low reporting costs (low $k_{c}$ ). Thus, the share of informed voters is larger there (high $\phi_{c}$ ) which implies larger amounts of grants. It also follows from the results in the media section that more grants are distributed to counties where the intrinsic utility of watching the news is high (high $\bar{u}_{c}$ ) and where the population is large (high $p_{c}$ ).

The next section outlines how these theoretical predictions can be empirically tested using data on United States television markets and the allocation of federal grant money across counties.

\section{Data and estimation approach}

With the theoretical idea that a politician will direct larger amounts of funds to counties where they generate more media attention comes the need to identify such places. The main argument in this paper is that television news programs are biased in favor of counties in the core area of a television market whereas distant counties receive only little attention. Thus, in order to measure this geographic determinant of voter information we need to identify the core areas of TV markets. To this end, we denote places that appear in the name of a media market defined by Nielsen Media Research as 'media centers' or 'media counties' and use as a main explanatory variable the distance of a county to the nearest media center.

The United States is split up into 210 of these media markets-called Designated Market Area (DMAs) - whose inhabitants tend to watch the same television stations. DMAs can cross state borders and are named after the city or cities where most TV stations are located (Fig. 1 shows DMA boundaries). ${ }^{5}$

Guided by the theoretical predictions, we expect public expenditure to generate more media coverage in counties that are media centers or are close to media centers because of lower reporting cost in the proximity of the stations' headquarters. This in turn leads to higher shares of informed voters and consequently to higher levels of funds. As the distances vary a great deal across DMAs, we use a relative distance measure calculated as county $c$ 's distance to the nearest media center divided by the average distance to a media center within $c$ 's DMA. The relative measure captures that TV stations divide their local news time mainly among events that occur within their own DMA.

We would ideally like to have as a dependent variable funds that politicians can freely distribute across their constituency. Since such monies are hardly ever available, the strategic use of resources is measured by the per capita amount of US federal grants allocated to counties in the 48 contiguous states in 2000. These grants are awarded in hundreds of programs ranging in focus from agriculture to health and the total amount awarded in 2000 was $\$ 309$ billion, or $\$ 1,050$ per capita. The allocation of funds across counties results from a complex political bargaining process. Many different actors

\footnotetext{
5 Whenever multiple cities of importance to the media market are present, they enter the DMA name (e.g. the San Francisco DMA is called San Francisco-Oakland-San Jose). When this is the case, our distance variable measures distance to the nearest city appearing in the DMA name.
} 


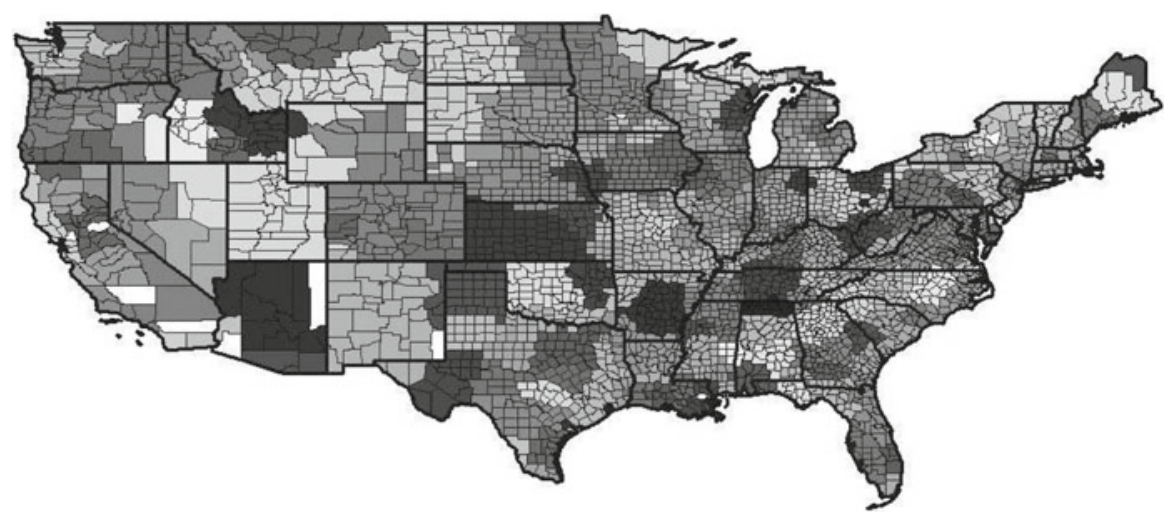

Fig. 1 DMAs and state borders

participate in this process, among them governors, senators, House members, mayors or private organizations. As we have already outlined in the theory section above, we tell the story paradigmatically from a governor's perspective. However, it is important to note that all politicians face incentives created by television market geography that affect political outcomes in the same way: regions where media activity is high receive favorable policies. ${ }^{6}$

The following baseline specification empirically represents this main concept of grant spending contingent on media coverage, which was derived in the theoretical model. All variables except for those measured in percentages are entered as logs:

$$
g_{c}=t_{d} \cdot \phi_{c}^{D}+t_{m}^{\prime} \cdot \phi_{c}^{M}+\eta^{\prime} x_{c}+\varepsilon_{c}
$$

Here, $g_{c}$ is the dollar amount of federal grants per capita awarded to county $c$. The share of informed voters $\phi_{c}$ from the theoretical model is proxied for by $\phi_{c}^{D}$, the county's distance to the nearest media center within its DMA. While this is our main predictor of grant spending, further media related variables that may also have an effect on the level of information in the population make up vector $\phi_{c}^{M}$. The control vector $x_{c}$ consists of socio-demographic county characteristics, political economics variables as well as a number of population and geography controls.

Additional TV market variables. The first variable in $\phi_{c}^{M}$ is the number of TV stations licensed in county $c$. Aside from being tantamount to zero distance to the nearest media outlet whenever the variable takes on values greater than zero, it accounts for possibly having multiple outlets at one's disposal. ${ }^{7}$ These stations are made up in large part of affiliates of the four big networks ABC, CBS, NBC, FOX plus the PBS stations. To these full-service stations we add stations that have been classified as 'Class-A' by

\footnotetext{
6 Studies by Albouy (2009a,b), Knight (2004) and Levitt and Snyder (1997) as well as Snyder and Strömberg (2010) also use federal grants as an outcome in research on the strategic distribution of resources.

7 The variable is calculated as $\log$ (number of TV stations +1$)$. The estimated coefficient $t_{m}^{\text {no }}$ will therefore not represent an elasticity. $t_{m}^{n o}$ can be transformed into an elasticity as follows: $t_{m}^{n o} \cdot[j /(j+1)]$, where $\mathrm{j}$ is the number of TV stations.
} 
the Federal Communications Commission (FCC). ${ }^{8}$ Taken together, there are over 850 counties which contain at least one station compared to about 340 media cities. The number of stations may be a predictor of federal grant spending, because having at least one media outlet in the immediate vicinity will increase chances of news being picked up on, even without being a media city. In addition, the variable captures possible competition effects in the local media market. We expect the variable's coefficient to bear a positive sign because the share of informed voters could be larger in counties with more TV stations. Obviously, all media center counties are host to at least one TV station and so the distance and number of TV stations variables are to some extent collinear.

As quite a few DMAs cross state borders, we add to $\phi_{c}^{M}$ an indicator for whether a county is 'out-of-state', i.e. all media cities in the DMA are located in another state than county $c$. It accounts for counties possibly being marginalized within their own DMA information-wise, because it may be more costly for TV stations from the media center to cover them. This could happen whenever networks for gathering information are state-specific, e.g. because they require connections to the state administration. This would effectively create a home-state-bias in reporting.

We also add the share of the DMA population located in the same state as county $c$. This variable may also measure marginalization, such that a smaller share means less media attention because stories from that state are of relevance to a smaller part of the total DMA audience. However, if county $c$ is not out-of-state and TV stations have a home-state-bias, a smaller share of DMA population located in the same state as $c$ might lead to higher grants, as the TV station caters to a smaller within-state audience among which the news time is divided. In an attempt to disentangle these effects, we add an interaction of the two variables.

Finally, we include the distance to the nearest media city outside the own DMA in order to check whether the 'distance to own DMA media center' variable merely measures distance to a metro area rather than a true media effect. We expect this variable to exhibit no significant relation to grant allocation.

Political economics controls. Theory advises to include variables measuring voter turnout $\left(\gamma_{c}\right)$ and voter mobility (the number of swing voters, $\psi_{c}$ ). The model predicts that high voter turnout as well as high voter mobility lead to more grant awards. Relative voter turnout in county $c$ is calculated as the share of the population that voted in the 1996 presidential election divided by the average turnout in the state that county $c$ is located in. Voter mobility is accounted for by including the number of times the majority in presidential elections in county $c$ has shifted from 1980 to $1996 .^{9}$

In addition, we include the distance to the state capital relative to all other counties in the same state. This measure is believed to be negatively related to federal grants due to the higher lobbying costs remote counties face (Borck and Owings 2003). A high percentage of residents employed by the federal or local government supposedly is associated with greater political influence and thus higher grants per capita.

\footnotetext{
8 'Class-A' stations are given protected status by the FCC because they convey local information. They are typically unaffiliated with networks and sometimes have lower reach than network TV stations.

9 The log of mobility is calculated as $\log$ (majority shifts +1 ).
} 
Because we do not have data on the number of politicians hailing from each county, we assume that the percentage of residents employed by federal, state and local governments in county $c$ is highly correlated with the number of political agents operating on behalf of county $c$. The government employment variables then also measure 'politician density' and thus account for differences in how well counties are represented in the political process. A Herfindahl index of ethnic fragmentation is included, because Alesina et al. (1999) find that fragmentation leads to higher intergovernmental spending. An index value of unity indicates a completely homogenous population. We add the white percentage of the population, because different ethnic compositions can result in the same Herfindahl index.

Sociodemographic and urbanity controls. The sociodemographic controls measure the financial needs of a county and therefore the relative importance of federal grants to different groups in the population $\left(\ell_{c}\right.$ in the model). In addition to the percentage of residents with at least a bachelor's degree, which is essentially another control for how informed voters are, we include per capita income, poverty rate, unemployment rate, share of females, percentage of high school dropouts, county expenditure per capita, percentage of population under 24 , bank deposits per capita and the ratio of mean to median income.

We must take care not to confound the effect of media outlets with general urban/rural characteristics that may lead to different levels of grant allocation. Thus, we include in $x_{c}$ the county population, land area, population growth in the 1990s, the county longitude and latitude, an indicator for counties of more than 200,000 inhabitants, an indicator for whether the county is classified as a metropolitan/micropolitan area, and population density. A nice side effect of adding these controls is that they should at the same time account for the attractiveness of a county for setting up a television station. As Greenberg (1969) states: 'station profitability depends primarily on audience size'. In the same vein, Gentzkow (2006) finds that it was counties with high population and population density that were historically most profitable for TV station owners. Consequently, these counties were the first to be granted television licenses and to this day the number of TV stations in a county is largely predicted by these variables. Adding the controls listed above thus reduces the potential for the coefficient on 'number of television stations' to be confounded with unobserved market size effects that may drive both the number of stations and grant allocation. All estimations allow for clustering of standard errors by state and include state fixed effects. Summary statistics are shown in Table 7 and variable descriptions in Table 8.

\section{Empirical results}

This part of the paper presents the baseline OLS estimations in Sect. 4.1. Because our two key variables hardly change over time, panel analysis in order to net out fixed county characteristics is not an option. ${ }^{10}$ Rather, we use a wide array of controls in

\footnotetext{
10 The number of major TV stations licensed in a given county shows only very limited variation over time, and the distance a county is located from the nearest media city is fixed. The only possible reasons for this distance to actually change would be for a county to change DMA affiliation. This rarely happens and
} 
order to isolate the association between the media and grant spending. Robustness checks and corrections for spatial dependency are shown in Sects. 4.2 and 4.3, respectively. In all estimations, the 48 counties containing the state capitals have been excluded from the analysis. As can be seen from Table 7, the average county in the sample excluding state capitals is awarded around $\$ 1,000$ per capita in grants. However, because some grants that cannot be attributed to a single county are assigned to the state capital, counties that contain the state capital receive about four times that amount. Since many of these counties are also media centers or at least contain a television station, including them would lead us to overestimate the effect of the media on grant spending. The sample used for the full specifications includes 2,934 counties because some controls are missing for a number of counties.

\subsection{The link between media activity and spending}

On a descriptive level, the connection between media proximity and federal grant distribution is far from clear. While the theoretical model predicts higher spending in the vicinity of media centers, the raw correlation between 'distance to media center' and grant spending is actually 0.15 , i.e. remote counties receive more rather than fewer grants. The same is true for the number of television stations and grants: the correlation is close to zero and not of the expected sign at -0.03 .

Column (1) of Table 1 shows that by simply adding the mean per capita income and state fixed effects to a regression, the negative correlation between grants and distance is reversed. The distance coefficient implies that being twice as far from a media center as the average county is associated with receiving 5\% fewer grants. This is consistent with the theoretical model. It predicts that politicians will spend less money in these remote counties because of the lower media coverage which in turn is due to the high cost of reporting from these places. Column (2) adds population and geography controls in order to correct the distance coefficient for the fact that most counties that are far away from the media center are also rural. While some of these urbanity controls are highly significant, the distance coefficient remains very stable. Even adding a wide range of sociodemographic controls in column (3) does not change the distance coefficient. It seems that, while many of these controls are highly significant, they are mainly related to income rather than the distance variable. An interesting result in this specification is that higher education levels in the population are positively related to received grants. Just as the negative coefficient on distance, this is in line with the idea of better informed voters receiving higher levels of grants. Seven political economics variables are introduced in column (4). All of the political variables have the expected sign and they are also the first controls to actually affect the distance coefficient. It is scaled down to three quarters its original size but remains highly significant.

Footnote 10 continued

thus the variation in the data will be insufficient to identify any effects. The stationarity is acknowledged by Gentzkow (2006), who assumes current DMA borders to be a valid approximation to those in the 1960s. 


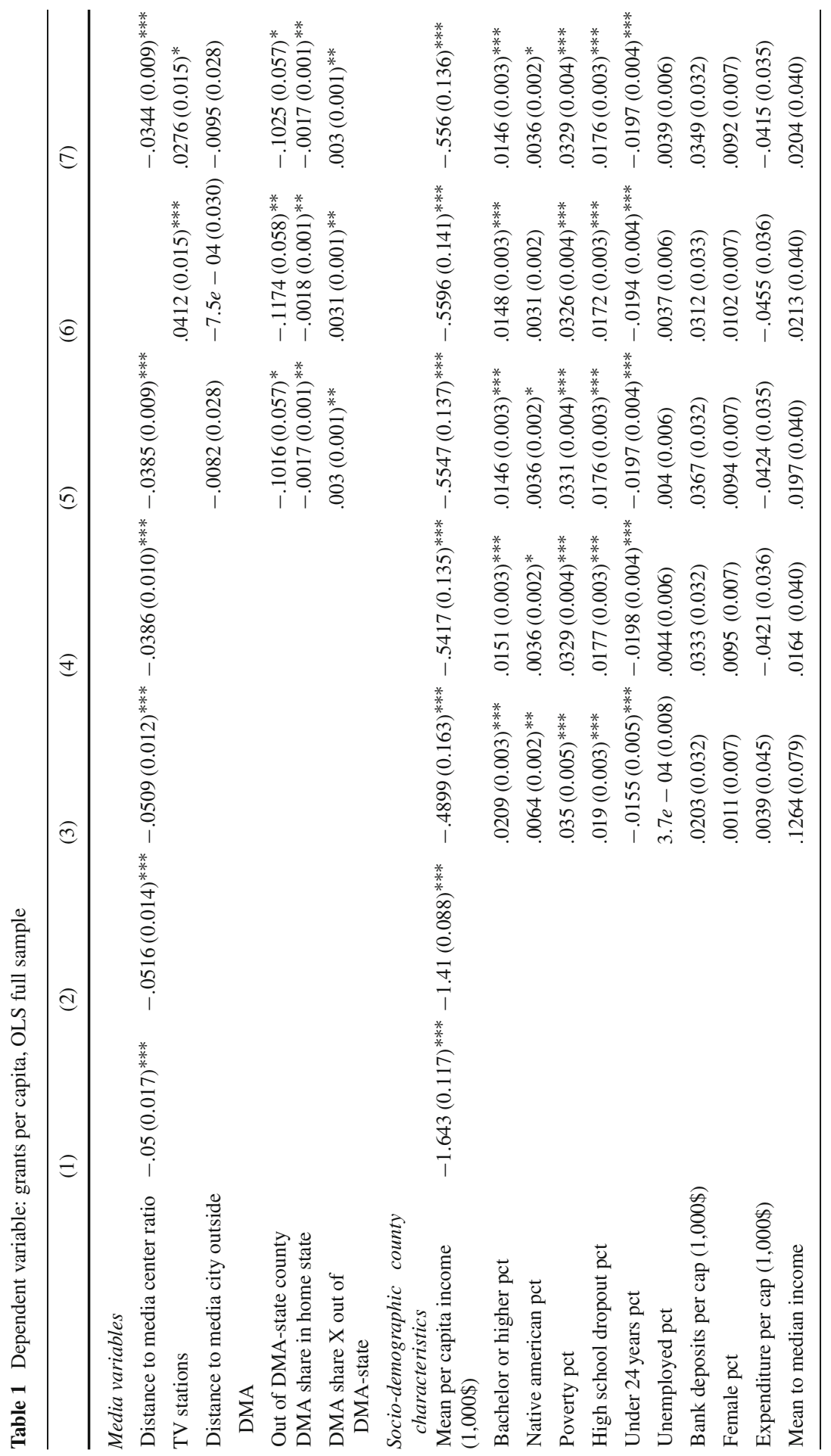




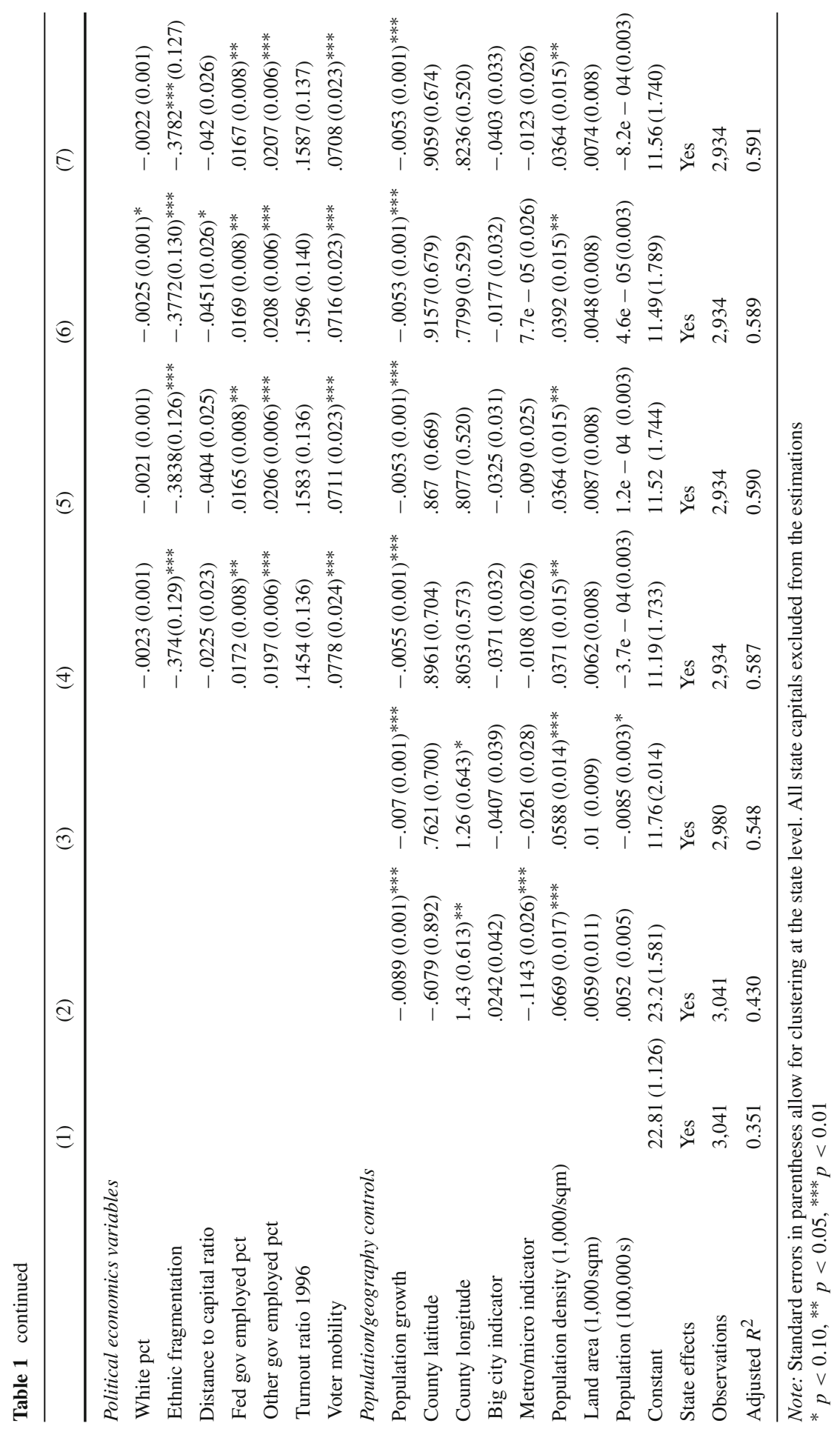


Even though we focus on the distance variable $\phi_{c}^{D}$, we are also interested in the other media variables which make up $\phi_{c}^{M}$. Column (5) adds the out of state indicator, the DMA home share and an interaction of the two. The sign of out-of-state counties is negative, consistent with the idea of higher cost of reporting from these counties and a resulting home state bias of TV stations. Keep in mind, though, that this is evaluated at a DMA home share of zero. For out-of-state counties, an increase in the home share is associated with a gain in grants, whereas in-state counties lose money when their DMA home share increases. This means that a county without a media city in its home state can make up for this disadvantage when its state's DMA home share is larger, because reporting from this state becomes relatively more profitable for TV station operators. For in-state counties the negative coefficient on home share implies that, given a homestate biased media city in your state, it is best shared with as few people as possible. The mechanism is the same as with the distance variable: the increased media attention leads to a higher probability of receiving information on the events concerning your county, which in turn will provide politicians with incentives to direct spending there.

As can be seen in column (6), having TV stations in the county also leads to higher grant awards, yet the effect decreases in the number of stations. As mentioned above, a pseudo-elasticity can be calculated as: TV station coefficient times $[j /(j+1)]$, where $j$ indicates the number of TV stations. Accordingly, the loss of the only TV station in a county incurs a drop in grants per capita of approximately $2 \%$ whereas an increase from 10 to 11 stations only generates $[10 \cdot 10 / 11] \cdot 0.04=0.35 \%$ more grants per capita. Finally, column (7) includes both the TV stations and the distance variable at the same time. As expected because of the collinearity, both coefficients are somewhat diminished. Most importantly, though, counties far from the nearest media center still receive significantly lower amounts of grants.

In sum, we find the hypothesized effect of our key variables. This leads to the conclusion that vote-maximizing politicians indeed seem to favor counties where media activity is high and counties less exposed to media coverage receive less attention when grants are distributed.

\subsection{Robustness checks}

Having established a positive link between media activity and grant spending, this section is concerned with how robust the results are to changes in specification and sample.

As a first robustness check, we employ a subset containing only the 1,652 micropolitan and metropolitan counties in the dataset. Figure 2 shows the counties by sample, where Metro/Micro counties are nested within the full sample. ${ }^{11}$ We are confident that the population and geography controls already take care of things such as scale effects, minimum grants per county leading to higher per capita grants in less populous counties, overrepresentation in the political process or flat rate grants per county. How-

\footnotetext{
11 Metro areas are defined by the Bureau of the Census as areas containing a core urban area of 50,000 or more population. Micropolitan areas contain an urban core of at least 10,000 population. Metro or micro areas include one or more counties, specifically the core urban area, as well as many adjacent counties. Around $80 \%$ of the US population resides in metropolitan areas.
} 


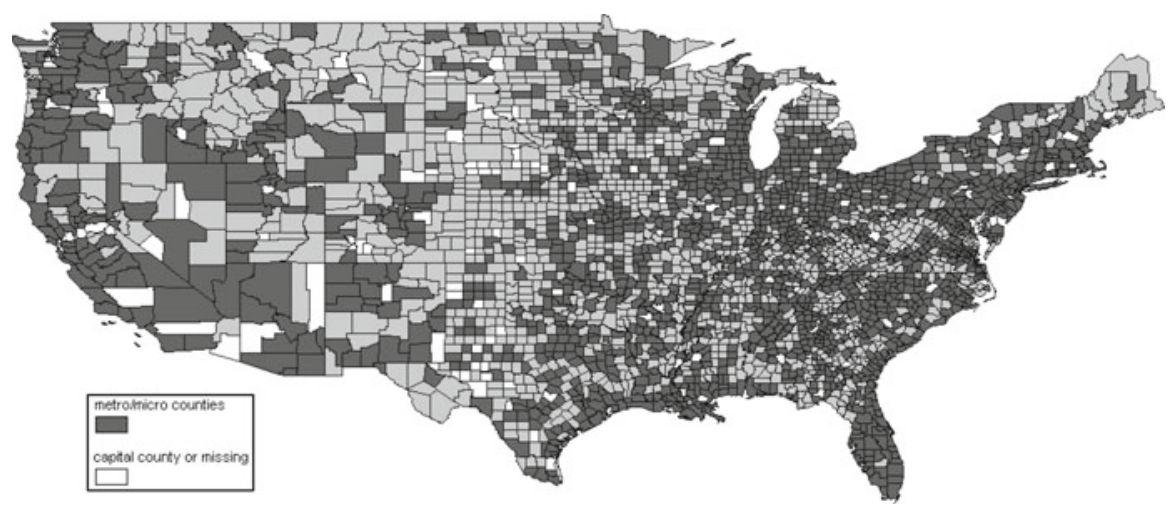

Fig. 2 Counties by sample. Dark shading: Metro/Micro counties

ever, in the event that there are other unobserved differences in urban and rural counties that affect both the media and grant spending, we try to account for this by estimating the same specifications as in Table 1 on the non-rural counties only. These estimates, shown in Table 2, are very similar to the ones obtained from the full sample. While the coefficient on distance is again highly significant and virtually identical to the full sample, the association between television stations and grant spending seems to be a bit stronger and more precisely estimated. The coefficients on out of state counties, the DMA home share and their interaction are almost identical to the full sample in terms of size and significance and are not reported here. The urban sample estimates therefore corroborate the earlier results.

In a second variation, we exclude Medicaid spending from the grants variable. Medicaid accounts for roughly half the federal grant money in our data and is also considered to be rather "fixed" (Levitt and Snyder 1997). Excluding these payments tests whether the media variables pick up health status in the population or some other health-related characteristic we have not controlled for. The specifications in columns (1)-(3) of Table 3 correspond to columns (5)-(7) in Tables 1 and 2. In four of the six specifications, the estimated media coefficients are now larger than before. While the coefficients on distance are larger in each of the estimations, the coefficient of television stations is larger in the urban sample and smaller in the full sample. The full sample coefficients are also less precisely estimated. The larger effects are in line with what we would expect if Medicaid cannot be influenced by political agents as much as other grant schemes. The fact that the TV coefficient actually decreases in the full sample weakens this argument somewhat, yet the hypothesized effects put forward in the earlier sections of the paper are still very much present and in most cases even strengthened.

The baseline estimates obtained so far may still be biased due to omitted variables, such as the presence of interest groups and lobbying activity. One could think of the agricultural sector or heavy industry as branches that have traditionally been successful in acquiring grants. Sheer economic size in terms of having many private businesses may also be advantageous to acquiring grants, since some of them go directly to business owners. To account for these factors, in Table 4 we add as controls the number of privately owned nonfarm businesses as well as indicator variables for the economic 


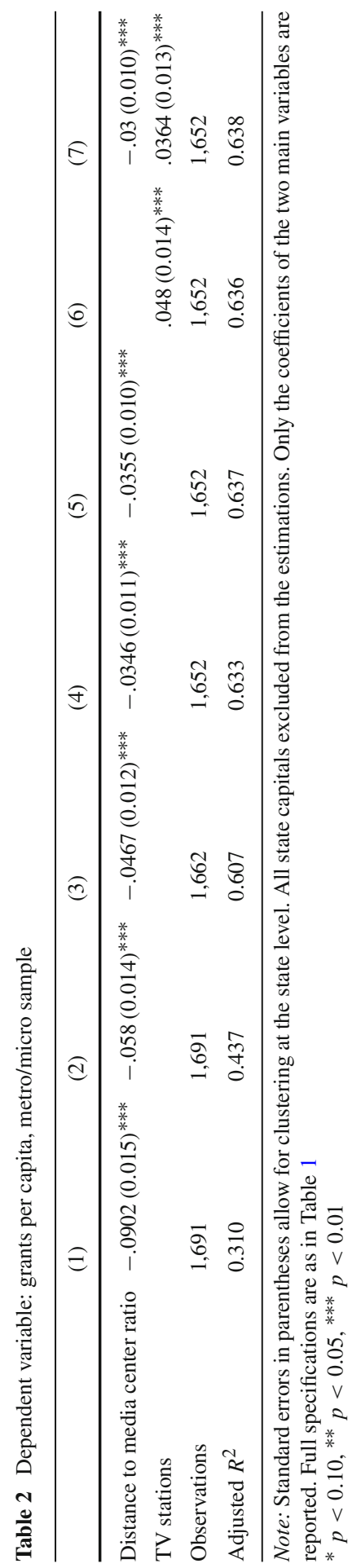


Table 3 Medicaid excluded

(1)

\section{Full sample}

Distance to media city ratio

Full service TV stations

Observations

Metro/micro sample

Distance to media center ratio

TV stations

Observations

$$
\begin{aligned}
& -.0443(0.011)^{* * *} \\
& 2,932 \\
& -.039(0.013)^{* * *} \\
& 1,650
\end{aligned}
$$

$$
-.0424(0.011)^{* * *}
$$$$
.0127(0.020)
$$

$$
2,932
$$$$
-.0327(0.013)^{* *}
$$$$
.0417(0.017)^{* *}
$$

1,650

Note: The dependent variable is 'grants per capita, excluding Medicaid'. Only media variable coefficients

\begin{tabular}{|c|c|c|c|c|}
\hline & \multicolumn{2}{|l|}{ Full sample } & \multicolumn{2}{|l|}{ Metro/micro } \\
\hline & (1) & (2) & (3) & (4) \\
\hline \multicolumn{5}{|l|}{ Full sample } \\
\hline Distance to media city ratio & $-.032(0.009)^{* * *}$ & $-.029(0.016)^{*}$ & $-.031(0.009)^{* * *}$ & $-.032(0.014)^{* *}$ \\
\hline Full service TV stations & $0.028(0.015)^{*}$ & $0.064(0.100)$ & $.038(0.014)^{* *}$ & $.021(0.092)$ \\
\hline $\begin{array}{l}F \text {-test county classifications, } \\
\quad F(5,47)\end{array}$ & 6.58 & & 5.39 & \\
\hline$F$-test instrument, $F(1,47)$ & & 27.32 & & 20.27 \\
\hline Observations & 2,934 & 2,933 & 1,652 & 1,651 \\
\hline
\end{tabular}
shown. The specifications in columns (1)-(3) correspond to columns (5)-(7) of Tables 1 (full sample) and 2 (metro/micro sample). All state capital counties $(n=48)$ excluded from the estimations. Standard errors in parentheses allow for clustering by state

${ }^{*} p<0.10,{ }^{* *} p<0.05,{ }^{* * *} p<0.01$

Table 4 Additional controls (1), (3) and IV estimates (2), (4)

Note: The dependent variable is 'grants per capita'. Only media variable coefficients shown. Columns (1) and (3) add further controls to the baseline specification in column (7) of Tables 1 (full sample) and 2. Columns (2) and (4) show IV estimates of column (7) from Tables 1 (full sample) and 2 (metro/micro sample). The instrument is the number of low power TV stations. All state capital counties $(n=48)$ excluded from the estimations. Standard errors in parentheses allow for clustering by state ${ }^{*} p<0.10,{ }^{* *} p<0.05,{ }^{* * *} p<0.01$.

type of a region. The indicators are based on a county's primary source of employment and classify them as farming-dependent, mining-dependent, manufacturing-dependent, federal/state government-dependent, services-dependent, or nonspecialized. The $F$-tests in columns (1) and (3) of Table 4 show that a county's specialization is significantly related to grants received. The number of businesses does not seem to be associated with grant spending (coefficient not reported). Most importantly, the coefficients of the media variables remain unchanged in magnitude and significance level.

Measurement error and reverse causality may be an issue, too. TV stations in our data are assigned to the county where the station is licensed or where the main transmitter is located. In most cases this will be identical with the county where the actual TV studio is located, but sometimes the two locations do not coincide, causing the 
TV stations variable to be measured with error. Because measurement error biases the estimates towards zero while we mainly want to avoid overestimating the media effect, we are not too concerned about it. Somewhat more of an issue is possible reverse causality. The location of TV stations may be endogenous to government spending, as they include PBS affiliates which are funded by the Corporation for Public Broadcasting (CPB), federal and state governments. As a first measure to account for this, CPB grants to local jurisdictions are already excluded from our dependent variable. Around 2000, these accounted for about $80 \%$ of federal money that went to public broadcasting. ${ }^{12}$ We also already control the main factors in the placement of television stations: population and population density. If stations emerge or are licensed where grant spending is higher due to reasons other than what is captured by our population and geography controls, we may still overestimate the effect of having a TV station in the county. Estimates from an IV approach to this issue are shown in columns (2) and (4) of Table 4. We instrument the number of TV stations with the number of low power (LP) TV stations that are not classified as Class-A (CA) and have low broadcasting power of less than $10 \mathrm{kw}$. Most of these stations are non-profit with a niche focus, e.g. educational, religious or other stations low in reach and information content that is of interest to a broad audience. Consequently these stations cater to very small audiences. Therefore they should not be targeted by politicians and their location should not be contingent on public spending or any kind of political clout a county may have. After controlling market size, the number of low power and full-service TV stations should be primarily correlated because of technical issues such as whether the geography of a county favors broadcasting. Despite finding a strong correlation in the first stage, the second stage confidence intervals of the TV coefficient include both the OLS coefficient and zero. While not very informative, the IV estimates shown in columns (2) and (4) of Table 4 thus do not preclude the baseline estimates.

The robustness checks support the notion that federal grant spending is related to differences in the amount of media attention a county gets due to its location. The very stable and highly significant coefficient on the distance variable contrasts with the less stable TV stations coefficient. However, $F$-tests show that the distance and TV stations variable are jointly significant at the .1\% level in all specifications. Taken together, these results corroborate the results from the baseline specification.

\subsection{Spatial dependencies in grant spending}

Another concern is that strategic interaction could be responsible for possible similarities between grants awarded to neighboring counties. Not correcting for such interdependencies may bias the media coefficients. One mechanism that can induce a positive correlation between neighboring counties' spending is yardstick competition. Because it requires two governments that strategically interact, yardstick competition may not be so relevant in the case of a governor distributing grants across his state. ${ }^{13}$ However,

\footnotetext{
12 See http://www.cpb.org or http://www.newenglandfilm.com/news/archives/00december/pbs.htm.

13 If people are envious of the amount of grants their neighboring counties receive, an interdependence would be introduced, such that the governor may have to abide to equity concerns and follow up a grant award to county A with an award to county B, creating positive correlation.
} 
Table 5 Spatial dependency-GS2SLS estimations

\begin{tabular}{llll}
\hline & $(1)$ & $(2)$ & $(3)$ \\
\hline $\begin{array}{l}\text { Distance to media } \\
\text { center }\end{array}$ & $-.039^{* * *}(0.009)$ & & $-0.035^{* * *}(0.009)$ \\
$\begin{array}{l}\text { TV stations } \\
\text { Spatially lagged } \\
\text { grants } \\
N\end{array}$ & $0.165^{* * *}(0.034)$ & $0.038^{* *}(0.015)$ & $0.025(0.015)$ \\
& 2,934 & $0.165^{* * *}(0.034)$ & $0.165^{* * *}(0.034)$ \\
\hline
\end{tabular}

Note: Only coefficients on main media variables and spatial lag of grants reported. Full specifications are as in column $(7)$ of Table 1 . All state capital counties $(n=48)$ excluded from the estimation. Standard errors in parentheses

${ }^{*} p<0.10,{ }^{* *} p<0.05,{ }^{* * *} p<0.01$

other political agents such as congressmen make strategic interaction seem more realistic, and strategic interaction can always occur in counties bordering another state. ${ }^{14}$ In addition, locally correlated shocks may lead to spatially correlated error terms, and thus to inefficient estimates. For these reasons, we estimate the three step spatial-IV estimator (GS2SLS) proposed by Kelejian and Prucha (1998). ${ }^{15}$ It takes into account the endogeneity of the spatially lagged dependent variable and allows for simultaneous presence of spatial lag and error:

$$
g=\rho W g+X \beta+\lambda W \varepsilon+u .
$$

Again, $g$ is a vector representing grant spending, $W$ is a spatial weight matrix and $W g$ gives the measure of grant spending in neighboring counties. The interaction between own and neighbors' spending is captured in $\rho$, which we would expect to have a positive sign in the presence of yardstick competition. Another reason for including the spatial lag could be spillovers in the provision of public goods, which we may not be able to capture in the baseline specification. In this case the spatial correlation expressed in $\rho$ may point in either direction. Spatial correlation in the errors is measured by $\lambda, \varepsilon$ is a vector of spatially autocorrelated error terms and $u$ is a vector of i.i.d. error terms. ${ }^{16}$

Estimations are carried out on the full sample only. Table 5 displays the coefficients on the media variables and the spatial lag of federal grant spending. We find highly significant positive spatial dependency, yet both our media variables remain virtually unaltered in comparison to the OLS results. We have already provided some intuition on what factors may be underlying the spatial effects, however this is not the focus of this research. We are content with being able to state that the significance in both media activity variables cannot be an artefact of spatial dependencies.

\footnotetext{
14 To some extent the variable DMA home share may be viewed as a measure of cross-state yardstick competition in our estimations, because a higher share of the DMA population living outside the home state implies getting more information about what is going on in the neighboring state. This may create yardstick competition among governors.

15 As suggested by Kelejian and Prucha (1998), we use the full set of spatially-first-lagged exogenous variables as instruments to account for the endogeneity of the spatial lag.

16 The weighting matrix $W$ is row standardized based on rook contiguity, i.e. counties sharing a common border are treated as neighbors.
} 


\section{Conclusion}

This paper analyzed the question of whether politicians allocate more funds to regions where they receive more coverage from local television. We developed a simple model which explains the incentives of TV stations to bias coverage towards the core area of a market, where the majority of these stations is located. This geographic bias was shown to create a specific distribution of political knowledge in the electorate: in the core areas, there are more voters who attribute funds to the respective politician than in remote areas. The resulting main prediction of the model is that politicians allocate more funds to the core regions because of higher payoffs in terms of votes.

Next, we carried out an empirical analysis to test this main theoretical prediction. Using data on the allocation of federal grants to US counties, we find evidence that public spending decreases in the geographical distance to the core areas of TV markets. This supports our theoretical contention that the well-known geographical bias in local television news programming affects public policy. In addition, the relation between TV markets and state borders seems to affect spending levels, too. The larger an in-state county's home state share of total market population, the lower the amount of grants the county receives. Interestingly, if a county is out-of-state this effect is reversed: if all media cities in the market are located in a neighbor state, a larger home state share is associated with higher funding levels.

Taken together, the empirical results provide evidence to support the theoretical argument that the geography of local television markets influences public policy. In particular, the main hypothesis on the relation between the distance to media cities and grant spending is very reliably confirmed. These findings contribute to the field of media and political economics the important aspect that the geography of media markets plays an important role for the allocation of public funds.

\section{Appendix}

See Tables 6, 7 and 8 .

Table 6 Counties by number of TV stations (incl. Class A)

\begin{tabular}{lcccc}
\hline $\begin{array}{l}\text { Number of } \\
\text { TV stations }\end{array}$ & \multicolumn{2}{l}{ Full sample } & \multicolumn{3}{c}{ Metro micro sample } \\
\cline { 2 - 5 } & Frequency & pct & Frequency & pct \\
\hline 0 & 2,149 & 73.24 & 1,019 & 61.68 \\
1 & 433 & 14.76 & 306 & 18.52 \\
2 & 129 & 4.40 & 113 & 6.84 \\
3 & 71 & 2.42 & 64 & 3.87 \\
4 & 50 & 1.70 & 48 & 2.91 \\
5 & 35 & 1.19 & 35 & 2.12 \\
\hline
\end{tabular}


Table 6 continued

\begin{tabular}{lcccr}
\hline \multirow{2}{*}{$\begin{array}{l}\text { Number of } \\
\text { TV stations }\end{array}$} & \multicolumn{3}{c}{ Full sample } & \multicolumn{3}{c}{ Metro micro sample } \\
\cline { 2 - 5 } & Frequency & pct & Frequency & \multicolumn{1}{c}{ pct } \\
\hline 6 & 15 & 0.51 & 15 & 0.91 \\
7 & 13 & 0.44 & 13 & 0.79 \\
8 & 5 & 0.17 & 5 & 0.30 \\
9 & 9 & 0.31 & 9 & 0.54 \\
10 & 8 & 0.27 & 8 & 0.48 \\
11 & 4 & 0.14 & 4 & 0.24 \\
12 & 2 & 0.07 & 2 & 0.12 \\
13 & 4 & 0.14 & 4 & 0.24 \\
14 & 2 & 0.07 & 2 & 0.12 \\
15 & 1 & 0.03 & 1 & 0.06 \\
16 & 2 & 0.07 & 2 & 0.12 \\
18 & 1 & 0.03 & 1 & 0.06 \\
24 & 1 & 0.03 & 1 & 0.06 \\
Total & 2,934 & 100.00 & 1,652 & 100.00 \\
\hline
\end{tabular}

Table 7 Summary statistics

\begin{tabular}{llllll}
\hline & $N$ & Mean & Std. Dev. & Min & Max \\
\hline Grants per capita (\$) & 2,934 & 1053.03 & 729.10 & 96.28 & 10937.40 \\
Grants per cap w/o Medicaid (\$) & 2,933 & 529.65 & 582.08 & 0 & 9986.81 \\
Distance to media center ratio & 2,934 & 1.01 & 0.57 & 0 & 3.36 \\
TV stations & 2,934 & 0.65 & 1.71 & 0 & 24 \\
Distance to media city outside DMA & 2,934 & 117.78 & 57.18 & 4.28 & 400.39 \\
Out of state county & 2,934 & 0.15 & 0.35 & 0 & 1 \\
DMA share in home state & 2,934 & 78.26 & 30.39 & 0.08 & 100 \\
Per capita income 1999 (\$) & 2,934 & 17,403 & 3822.02 & 7,069 & 44,962 \\
Bachelor or higher pct & 2,934 & 13.19 & 6.28 & 3.70 & 53.40 \\
Native american pct & 2,934 & 1.49 & 5.43 & 0 & 86 \\
Poverty pct & 2,934 & 14.11 & 6.40 & 2.11 & 50.88 \\
High school dropout pct & 2,934 & 30.770 & 10.23 & 4.50 & 68.40 \\
Under 24 years pct & 2,934 & 34.34 & 4.29 & 20.20 & 66 \\
Unemployed pct & 2,934 & 4.76 & 2.53 & 0.70 & 27.60 \\
Bank deposits per cap $(1,000 \$)$ & 2,934 & 2.33 & 0.46 & -0.17 & 4.69 \\
Female pct & 2,934 & 50.47 & 1.86 & 32.75 & 57.44 \\
Expenditure per cap $(1,000 \$)$ & 2,934 & 2.24 & 0.86 & 0.02 & 10.48 \\
Mean to median income & 2,934 & 1.68 & 0.27 & 0.80 & 10.13 \\
White pct & 2,934 & 85.16 & 15.59 & 12.60 & 99.5 \\
Ethnic fragmentation & 2,934 & 0.76 & 0.18 & 0.27 & 0.99 \\
\hline & & & & & 0 \\
\hline
\end{tabular}


Table 7 continued

\begin{tabular}{llllll}
\hline & $N$ & Mean & Std. Dev. & Min & Max \\
\hline Distance to capital ratio & 2,934 & 101.18 & 53.76 & 3.75 & 362.08 \\
Fed gov employed pct & 2,934 & 0.69 & 1.22 & 0.04 & 37.25 \\
Other gov employed pct & 2,934 & 6.57 & 2.83 & 2.25 & 52.53 \\
Turnout ratio 1996 & 2,934 & 99.65 & 13.52 & 16.45 & 185.33 \\
Voter mobility & 2,934 & 0.72 & 0.83 & 0 & 3 \\
Nonfarm businesses & 2,934 & 2,048 & 7,004 & 13 & $2,19,933$ \\
Farming-dependent cty & 2,933 & 0.14 & 0.34 & 0 & 1 \\
Mining-dependent cty & 2,933 & 0.04 & 0.19 & 0 & 1 \\
Manufacturing-dep. cty & 2,933 & 0.30 & 0.46 & 0 & 1 \\
Fed/state gov.-dep. cty & 2,933 & 0.11 & 0.31 & 0 & 1 \\
Services-dep. cty & 2,933 & 0.10 & 0.30 & 0 & 1 \\
Nonspecialized cty & 2,933 & 0.31 & 0.46 & 0 & 1 \\
Population growth & 2,934 & 11.20 & 15.84 & -26.31 & 191.04 \\
County latitude (rad) & 2,934 & 0.67 & 0.08 & 0.85 & 0.43 \\
County longitude (rad) & 2,934 & -1.60 & 0.20 & -1.18 & -2.17 \\
Big city indicator & 2,934 & 0.16 & 0.37 & 0 & 1 \\
Metro/micro indicator & 2,934 & 0.56 & 0.50 & 0 & 1 \\
Population density (1,000/sqm) & 2,934 & 0.17 & 0.64 & 0 & 16.40 \\
Land area (1,000 sqm) & 2,934 & 0.96 & 1.29 & 0.02 & 20.05 \\
Population (100,000s) & 2,934 & 0.84 & 2.82 & 0 & 95.19 \\
\hline
\end{tabular}

Table 8 Description of variables

\begin{tabular}{ll}
\hline Variable & Description \\
\hline
\end{tabular}

Dependent variables $^{\mathrm{a}}$

Grants per capita (\$)

Grants per cap w/o Medicaid (\$)

Media related variables ${ }^{\mathrm{b}}$

TV stations

Distance to media center ratio

Distance to media city outside DMA

DMA share in home state

Out of DMA-state county
Federal grants per capita, taken from the Consolidated Federal Funds Report (CFFR)

Federal grants per capita (CFFR), without Medical Assistance Program (Medicaid)

From the Federal Bureau of Communications Wireless Telecommunications Bureau Database 2006. Earlier versions of the database could not be obtained, yet the number of TV stations does not change much over time

Distance to nearest media city in county c's DMA, divided by the average distance to the nearest media city across all counties in the same DMA as county $c$

Distance to nearest media city outside county c's DMA

The share of the total population in county $c$ 's DMA that lives in county $c$ 's state

A county $c$ that belongs to a DMA with no media city in county $c$ 's state 
Table 8 continued

Variable Description

Sociodemographic controls ${ }^{\mathrm{c}}$

Per capita income 1999 (1,000\$)

Bachelor or higher pct

Native american pct

Poverty pct

High school dropout pet

Under 24 years pct

Unemployed pct

Bank deposits per cap $(1,000 \$)$

Female pct

Expenditure per cap $(1,000 \$)$

Mean to median income

Politics controls ${ }^{\mathrm{d}}$

White pct

Ethnic fragmentation

Distance to capital ratio

Fed gov employed pct

Other gov employed pct

Turnout ratio 1996

Voter mobility

County classification

Private businesses

Geography and urbanity controls ${ }^{\mathrm{e}}$

Population growth

Latitude

Longitude

Big city indicator

Metro/micro indicator

Population density $(1,000 / \mathrm{sqm})$

Land area (1,000 sqm)

Population (100,000s)
Per capita income 1,999 in $1,000 \$$

Share of the population that holds at least a bachelor's degree

Share of the population that is native American.

Share of the population in poverty

Share of the population that does not possess a high school diploma Share of the population that is under 24 years of age

Share of the population that is unemployed

Average amount of bank deposits per capita in county $i$

Share of the population that is female.

Total local expenditures per capita in $1,000 \$$

Mean per capita income divided by median per capita income

Share of the population that is white

Herfindahl index of ethnic fragmentation, 1 if homogenous.

Distance to county $c$ 's state capital, divided by avg. distance to capital across all counties in the same state as county $i$

Share of population employed by federal government (non-military)

Share of population employed by state and local governments

Number of democratic and republican votes cast in the 1996 presidential election divided by population of that year, relative to the average turnout in the state county $c$ is located in Number of times the majority in presidential elections in county c has shifted from 1980 to 1996

Main source of employment. Provided by US Department of Agriculture Economic Research Service

Number of privately owned nonfarm businesses

County population change 1990-2000 (\%)

County centroid latitude (rad)

County centroid longitude (rad)

Takes on value 1 if county population $>100,000$

Takes on value 1 if county is part of a statistical metropolitan or micropolitan area

Population per square mile

In square miles

County population

\footnotetext{
${ }^{a}$ Washington, D.C. is excluded as are counties that cannot be unambiguously assigned to a single media market

b,c,d,e Taken from County Databook 2000 published by the US Census Bureau, County Profiles published by the US Department of Agriculture (available online at http://maps.ers.usda.gov/profiles/ webcensusdownload.aspx) and County Quickfacts provided by the US Census Bureau
} 
Open Access This article is distributed under the terms of the Creative Commons Attribution Noncommercial License which permits any noncommercial use, distribution, and reproduction in any medium, provided the original author(s) and source are credited.

\section{References}

Adams WC (1980) Local television news coverage and the Central City. J Broadcast 24(2):253-265

Albouy D (2009a) The unequal geographic burden of federal taxation. J Polit Econ 117(4):635-667

Albouy D (2009b) Partisan representation in congress and the geographic distribution of federal funds. NBER Working Papers No. 15224

Alesina A, Baqir R, Easterly W (1999) Public goods and ethnic divisions. Q J Econ 114(4):1243-1284

Althaus SL, Trautman TC (2008) The impact of television market size on voter turnout in American elections. Am Polit Res 36(6):824-856

Besley T, Burgess R (2002) The political economy of government responsiveness: theory and evidence from India. Q J Econ 117(4):1415-1452

Borck R, Owings S (2003) The political economy of intergovernmental grants. Reg Sci Urban Econ 33(2):139-156

Dixit A, Londregan J (1996) The determinants of success of special interests in redistributive politics. J Polit 58:1132-1155

Gentzkow M (2006) Television and voter turnout. Q J Econ 121(3):931-972

Greenberg E (1969) Television station profitability and FCC regulatory policy. J Ind Econ 17(3):210-238

Hamilton JT (2004) All the news that's fit to sell: how the market transforms information into news. Princeton University Press, Princeton

Heider DB (2000) White news: why local news programs don't cover people of color. Lawrence Earlbaum Associates, Mahwah

Horrigan J, Garrett K, Resnick P (2004) The internet and democratic debate. Pew Internet \& American Life Project, USA

Kaniss PC (1997) Making local news. University of Chicago Press, Chicago

Kelejian HH, Prucha I (1998) A generalized spatial two stage least squares procedure for estimating a spatial autoregressive model with autoregressive errors. J Real Estate Financ Econ 17(1):99-121

Knight B (2004) Legislative representation, bargaining power, and the distribution of federal funds: evidence from the US Senate. NBER Working Papers No. 10385

Lee FE (2003) Geographic politics in the US House of representatives: coalition building and distribution of benefits. Am J Polit Sci 47(4):714-728

Levitt S, Snyder J (1997) The impact of federal spending on House election outcomes. J Polit Econ 105(1):30-53

Lindbeck A, Weibull J (1987) Balanced-budget redistribution as the outcome of political competition. Public Choice 52:273-297

Napoli PM, Yan MZ (2007) Media ownership regulations and local news programming on broadcast television: an empirical analysis. J Broadcast Electron Media 51(1):39-57

Persson T, Tabellini G (2000) Political economics. MIT Press, Cambridge

Snyder J, Strömberg D (2010) Press coverage and political accountability. J Polit Econ 118(2):355-408

Strömberg D (2004a) Mass media competition, political competition, and public policy. Rev Econ Stud 71(1):265-284

Strömberg D (2004b) Radio`s impact on public spending. Q J Econ 119(1):189-221 